Victoria Steele

\title{
Exposing hidden collections The UCLA experience
}

n September 2003, nearly 200 librarians and archivists gathered at the Library of Congress for a conference entitled "Exposing Hidden Collections." Organized by the Association of Research Library's (ARL) Special Collections Task Force, the conference addressed the challenges of providing access to uncataloged and unprocessed archival, manuscript, and rare book materials.

One of the overriding themes that emerged from the discussions was that while the hidden collection problem is a national and even international one, solutions to it must be found at the local level. Conferees agreed that each institution must assume responsibility for its backlogs, especially given the distinctive nature of each collection.

As we approach the fifth anniversary of the hidden collections conference, we in UCLA's Department of Special Collections take satisfaction in the strides we have made to address what was-and is-a considerable

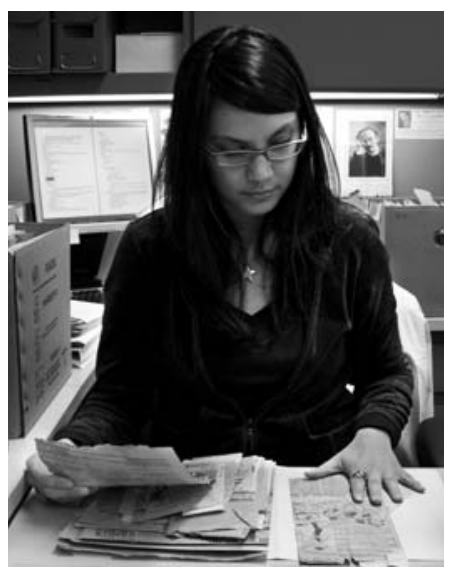

CFPRT Fellow Joanna Steele processing the papers of juvenile justice pioneer Judge Benjamin Barr Lindsey. Photograph by Mauricio Hermosillo.
CFPRT pairs graduate students with unprocessed or underprocessed collections in their areas of interest and trains them in archival methods, resulting in processed collections for us and dissertation, thesis, or research topics for them. CFPRT was launched in 2004 with start-up funds of $\$ 300,000$ donated by the Ahmanson Foundation. Since then, 59 student scholars have processed 126 previously inaccessible collections, amounting to nearly 1,000 linear feet. ${ }^{1}$

CFPRT has proved to be a great success. Students are enthusiastic about working with materials relevant to their personal educational goals, and they have been producing highquality, high-value finding aids and cataloging.

Their enthusiasm has been matched by that of the faculty, who are pleased to see their students finding viable research projects in their own backyard. In addition, by providing financial support to graduate students - they are paid at a rate equivalent to a teaching assistantship-CFPRT benefits the university at large, aiding in recruiting top students and accelerating and focusing the progress of students to the completion of their degrees.

CFPRT has also proved to be an attractive gift opportunity, especially for donors inter-

Victoria Steele is head of the department of special collections at UCLA's Charles E. Young Research Library, e-mail:vsteele@library.ucla.edu

๑) 2008 Victoria Steele 
ested in supporting students. In addition to the Ahmanson Foundation's start-up funds, CFPRT has attracted more than $\$ 100,000$ in operational funding. And, as of this writing, CFPRT has received gifts and pledges of $\$ 1$ million towards an endowment.

CFPRT is attracting attention as a model for other institutions grappling with hidden collections. Similar programs have been launched at Columbia University and Johns Hopkins University; and other libraries are actively pursuing funding to create their own programs to engage graduate student in providing access to hidden collections.

\section{Strategies for addressing hidden collections}

Another of our strategies for addressing hidden collections problem has been to seek foundation funding to process priority collections. For instance, thanks to a gift from the Steinmetz Foundation, we have been able to process the Orsini Collection, an archive consisting of 582 boxes documenting the history, over 800 years, of an Italian noble family. Another gift from this foundation is allowing us to process the papers of Nobel Peace Prize Laureate Ralph J. Bunche. Funds from the Getty Foundation enabled us to process five collections of art-related interest, including 1,240 boxes of the paper of

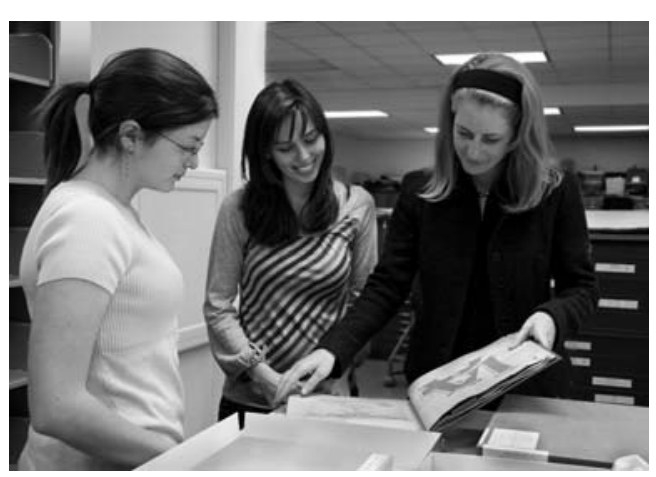

From left to right, CFPRT Fellows Audra Eagle and Amelia Acker, and CFPRT Coordinator Kelley Wolfe Bachli examining a scrapbook from the Japanese American Research Project. Photograph by Mauricio Hermosillo. the modernist architect Richard Neutra. The John Randolph Haynes and Dora Haynes Foundation provided support to process 125 boxes of material relating to Southern California history. CLIR/Mellon funds allowed us to hire a post-doctoral fellow who processed two large collections of Turkish manuscripts. A National Endowment for the Humanities grant is allowing us to process and digitize the Minasian Collection, one of the most extensive post-classical Islamic manuscript collections in the United States. Still other private funding has allowed us to process the Susan Sontag Papers; the Bonnie Cashin Collection of Fashion, Theater and Film Costume Design; and the Carey McWilliams Papers. We are also in the final stages of securing grant funding to tackle our large backlog of uncataloged rare books.

Despite our efforts to make inroads on our backlogs, we still have at least 300 completely unprocessed manuscript collections. But now, in contrast to past practice, when we accession an archival collection, we do so with a plan for its processing, which might involve asking the donor for funds, slating the collection for processing through CFPRT, or hiring temporary staff. To help with cost projections and to concretize the financial implications of accepting collections, we have prototyped an online estimator of processing costs. The estimator includes variables for size, level of staff, supplies, and other costs, such as moving collections. Adopting this strategy helps us to operate more like a business would, with future costs acknowledged, assessed, and weighed up front.

A key recommendation that emerged from the "Exposing Hidden Collections" conference was that internal funding be reallocated to tackle hidden collections. One way to implement this recommendation is to commit acquisitions funds for rare book cataloging projects. The political risks in making such a commitment are not to be taken lightly, but UCLA's library administration agreed to do so during one fiscal year in order finally to catalog a 5,000-volume collection of fantasy and science fiction that was purchased more than 40 years ago at considerable expense.

Another recommendation of the hidden collections conference was that institutions

(continues on page 331) 
Many of these resources will also be available in Spanish.

\section{Why does ALA need meeting effectiveness resources?}

One of the most common functions served by leaders in the association and by librarians nationwide is their capacity to conduct productive meetings and guide individual participation in group efforts. Yet, many professional librarians avoid leadership duties and positions because they feel overwhelmed with all they are expected to do. Their anxiety is further heightened because frequently their weak facilitation skills make them unable to organize others and produce results. By improving the facilitation skills employed by the leadership of ALA, these abilities will be passed on in meetings through example and expectation to future leaders, thereby enhancing the natural process of succession within ALA and increasing the pool of capable and willing members.

ALA wants to help the whole organization by focusing on individual needs.

"Making the Meeting" resources are available online at www.ala.org/makingthemeeting. $n$

\section{("Exposing bidden collections" continued from page 317)}

provide as much Web-accessible information about their manuscript materials as possible. Participants were asked to encourage their institutions to provide collection-level records for all collections, especially unprocessed ones. But many special collections are still engaged in retrospective conversion of the finding aids for their processed collections, and UCLA's Department of Special Collections is no exception.

Out of a total of some 1,700 collections, we have converted finding aids for more than 1,400 - the highest number in the State of California. ${ }^{2}$ But this has not been an easy task. Most of the work has been done on soft money, requiring continual efforts to obtain funds to sustain the project. Now, on a permanent basis, a team of two continues conversion of legacy finding aids and attends to revisions and additions to existing online finding aids. Even though encoding legacy finding aids is a labor-intensive undertaking, it is an effort that immeasurably benefits our researchers. As new finding aids become viewable online, we have seen, over and over, that researchers are at our door to consult the collections they describe. But it must be said that a consequence of our success has been that staff whose primary focus was the processing of collections are now almost wholly engaged in handling reader requests, reference inquiries, and licensing agreements-leaving them almost no time for processing.
A final strategy advised by participants in the ARL conference was that of expanding access to hidden collections by leveraging digitization efforts, and at UCLA we have done so by means of a number of projects. The most ambitious of these was to select and digitize 5,700 published and unpublished black-and-white newspaper photographs from the Los Angeles Times and from the Los Angeles Daily News photographic archives. ${ }^{3}$

Funded by the California Digital Library, the project involved selecting images from a collection of negatives, estimated to number between 3 and 4 million, that capture the development and culture of Los Angeles from the late 1800s through 1989. This project allowed us to create a new scholarly resource that is attracting considerable excitement and use.

If local action is the heart of the emerging national strategy for addressing the challenges of hidden collections, UCLA has shown that, even when budgetary times are lean, it can find opportunities and creative solutions for meeting those challenges.

\section{Notes}

1. See www2.1ibrary.ucla.edu /specialcollections/researchlibrary/12280. cfm.

2. See Www.oac.cdlib.org/institutions /ark:/13030/tf129008pn.

3. See unitproj.library.ucla.edu/dlib/lat. $\boldsymbol{n}$ 